\title{
浅析 “互联网+”在初中英语学科教学中的应用
}

\author{
王蓉 \\ 宁夏石嘴山市第八中学 \\ DOI:10.32629/er.v2i1.1632
}

[摘要] “互联网 + ”时代的到来, 不仅给英语学科教学带来了新的挑战,还促进了初中英语教学的改革与创新。课堂是教育 教学的主阵地,课堂教学需要注入更多的新元素。因此, 在 “互联网 + ” 背景下高效地、充分地利用网络教学环境、网络教学 资源进行初中英语教学模式的创新, 使之焕发生机和活力,这对促进初中生英语的有效学习以及自主学习均产生了积极作用。

[关键词] “互联网+”; 初中英语; 应用

\section{1 “互联网+”对初中英语教学的影响}

1. 1 促进教学模式的创新

“互联网+”既改变了传统初中英语教学体系中教师单 向地向学生进行英语知识的传授、“填鸭” 模式。在 “互联 网+”背景下, 英语教师也不再占据英语教学的主导地位, 各 种教学模式也在逐步进入初中英语课堂教学中, 学生不仅可 以在英语课堂上学到知识, 还可以在课外获取更多丰富的知 识。因此, “互联网+” 的发展也极大地促进了初中英语教学 模式的改革与创新。

1. 2改变学生的学习方式

在 “互联网+”背景下, 不但让初中英语课堂具备了 “双 向” 知识传递的能力, 而且让学生能够利用 “互联网 + ” 实现 自主学习, 使其拥有更多的学习方式和学习渠道。另外, 在 “互联网+” 背景下, 师生之间的 “教” 与 “学”, 互动增强, 教师可以利用 “互联网+” 实时掌握学生英语学习进度、效 果以及努力情况等, 而学生也可以随时随地地利用 “互联网
+” 向英语教师提出自己的疑惑与不解, 进而达到提高学生英 语学习效率的目的。同时, 也更新了学生从教师、教材中获 取知识的途径。

\section{2 “互联网+”在初中英语教学中的应用}

2.1 “互联网+” 在初中英语语音教学中的应用

语音教学, 由于受到各种各样因素的干扰和技术条件、 地理位置、方言的影响, 而变得越来越复杂。在二十世纪八 九十年代, 语音教学采用的是国际音标教学, 教师教给学生 发音, 解决学习英语存在的拼读障碍, 帮助学生拼读单词和 记忆词汇。这的确一种很大的进步。但是毕竟不同的教师, 发音的口型和发音轻重程度的把握不一致, 造成了不同班级 的学生的发音大相径庭, 甚至有的是怪腔怪调, 五花八门。到 了 21 世纪, 随着互联网的普及, 大量的语音信息资源出现在 互联网上, 有国际音标拼读发音规则和视频, 英美国家地地 道道的语音音频材料等。国内的一些英语学习网站还推出了 真人发音视频, 这就为语音教学的统一化、标准化提供了可

\section{4 结束语}

应用型大学的转型是本校的期望, 应用型人才是转型的 检验。课堂能够跟随工业技术的发展, 国家的需要, 才能真正 实现人才有用。该 $\mathrm{AGV}$ 小车围绕国家战略发展, 从整体到单 一零件, 从概念到功能, 从一门课程到大学整个教学体系都 能够融入课堂。学生能够根据实物认知知识, 根据理念发挥 想象, 根据设计完成产品, 能够提高学生的认知度, 成就感, 兴趣感和使命感。通过课程的设计, 项目的制作, 让学生对大 学生活不再是枯燥乏味, 让大学课堂真正的交到学生手中, 学生才是课堂的主人。

\section{[参考文献]}

[1]张春林.机械原理[M].北京:高等教育出版社,2006:24+35.

[2]常斗南.可编程序控制器原理 - 应用 - 实验[M]. 北京: 机械工业出版社,2008(5):36.

[3]史亚贝,刘欣宁. 采用 AGV 小车的柔性生产线技术方案 设计[J].机械设计与制造,2017(07):118-120.

[4]刘光涛, 马玉汉.智能控制小车在教学中的应用研究 [J].湖北成人教育学院学报,2018(02):75-78. 学习学生更加融入课堂。 
能。因而, 语音教学变得规范化, 学生学习到的语音也是一致 的, 更便于口语交流及翻译等。

\section{2 “互联网+” 在初中英语听说教学中的应用}

近几年, 中学英语教材的出版商为自己出版的教材配备 了相应的语音阅读。但是这些语音材料与现实生活之间差距 太大, 给学生以呆板、枯燥和乏味的感觉, 无法激发学生的情 感和兴趣。所以, 一线教学的教师, 有必要拓宽自己的信息渠 道, 充分利用互联网上丰富的听力材料和口语教学资源, 优 化自己的听说教学。例如:

2.2.1 每天利用早自习的时间, 让学生听 5 分钟的音视 频材料, 接着要求学生跟着模仿, 等到大家都熟练了以后, 要 求学生对说听到的内容进行复述, 听写、默写。坚持不懈、 学生就渐渐地习惯了 VOA 和 BBC 的语音语调, 甚至能够利用 这些风格的语音语调进行模仿训练, 达到事半功倍的效果。

2.2.2 教师可根据学生年龄段的特点, 从互联网上下载一 些学生喜闻乐见的英语故事的音视频材料, 让学生在班级或者 是适当的场合进行模拟表演, 达到训练英语听说能力的目标。

2.2 .3 使用手机下载 “英语趣配音”, 每周进行一个模 拟配音, 并上传自己的作品。每周进行评选, 分别评选出 “最 佳配音奖”、“最佳创意奖”、等奖项。这样的活动极大地激 发了学生练习口语以及学习英语的热情, 而且配音的内容语 言纯正, 让学生零距离接触地道的英语, 很大程度地促进了 英语语言能力的提升, 这样也达到了教学的目的。

\section{3 “互联网+” 在初中英语阅读教学中的应用}

在阅读过程中, 教师要结合生词创设情景, 再结合情景 来讲故事。利用 “互联网+” 活化情景, 拉近情景与学生日常 生活的距离, 以期达到让学生在阅读中学习单词和理解词义 的目的。以 JEFC Lesson100 为例, 可将本文划分为六个画面:
(1) a picture of bedroom (2) a picture of living room (3) a picture of dining room (4) My mother cooks for us, but my father cannot cook well. (5) After dinner, I wash the dishes.

(1) - - (3) 都使用视频编辑推出三张画面: bedroom, living room, dining room. 使用课文的语言来描述这三类 地点。然后将画面定格在 dining room 上, 让学生用 There be 句形来描述客厅的情况。(4) 将画面切换成父母在做饭。让 学生描述父母做饭的熟练程度。(5) 将画面切换为我在洗盆 子。闪出并教授 wash 和 dish 两个单词。

让学生按画面出现顺序一一描述课文。“互联网+”生动 形象的动画效果给学生留下深刻的印象, 使学生尽快理解词 义, 有助于学生巩固对生词的记忆。另外, 看图说话能当堂训 练学生的单词应用能力, 也有助于学生全面素质的提高。

综上所述, “互联网+”在初中英语学科教学中的应用非 常广泛, 但是我们也应该清醒地认识到: “互联网+”对学生 英语能力的具体提升, 还需要教学一线老师的坚韧不拔的努 力。“世上无难事, 只怕有心人”。充分利用互联网信息和技 术, 为英语教学服务, 是每一个英语教师的必备的素养。

\section{[参考文献]}

[1]周有权.网络环境下的初中英语教学[J].中国教育技 术装备,2010(7):184.

[2]贾光富.论信息技术与英语教学的整合[J].新乡教育 学院学报,2003(1):45-47.

[3]周玲. 现代信息技术在中学英语教学中的实际应用 [J].教育教学论坛,2014(38):238-239.

[4]李广谦. 多媒体教学手段在中学英语教学中的运用 [J].新课程研究:基础教育,2009(8):170-171. 